\title{
Various Cooking Methods and the Flavonoid Content in Onion
}

\author{
Kana Ioku, Yuka Aoyama, Ayaka ToKuno, Junji Terao ${ }^{1}$, Nobuji NAKATANI ${ }^{2}$ and Yoko TAKei \\ Faculty of Education, Osaka Kyoiku University, Kashiwara 582-8582, Japan \\ ${ }^{1}$ Course of Nutrition, School of Nutrition, The University of Tokushima, Tokushima 770-8503, Japan \\ ${ }^{2}$ Department of Food and Nutrition, Faculty of Human Life Science, Osaka City University, Osaka 558-8585, Japan
}

(Received March 13, 2000)

\begin{abstract}
Summary Onion is a major source of flavonoids and is cooked in various ways in the world. The major flavonoids in onion are two quercetin glycosides, quercetin $4^{\prime}$-O- $\beta$-glucoside $\left(\mathrm{Q} 4^{\prime} \mathrm{G}\right)$ and quercetin $3,4^{\prime}-\mathrm{O}-\beta$-diglucosides $\left(\mathrm{Q} 3,4^{\prime} \mathrm{G}\right)$, which are recognized as bioactive substances that are good for our health. We have investigated the effect of cooking procedures on the content of antioxidants. We selected quercetin conjugates, total phenol compounds, and ascorbic acid to estimate the amount of flavonoid ingestion from onion. We examined the following cooking methods: boiling, frying with oil and butter, and microwave cooking. Various cooking methods do not consider the degradation of quercetin conjugates when cooking onion. Microwave cooking without water better retains flavonoids and ascorbic acid. Frying does not affect flavonoid intake. The boiling of onion leads to about $30 \%$ loss of quercetin glycosides, which transfers to the boiling water. At that time, the effect of additives on the quercetin conjugates is different according to the compounds. The hydrolysis of quercetin glycosides for daily cooking might occur with the addition of seasonings such as glutamic acid. Additional ferrous ions accelerated the loss of flavonoids.
\end{abstract}

Key Words cooking, onion, flavonoid, quercetin

Onion (Allium cepa L.) is thought to be a major source of flavonoids, especially quercetin, and continues to attract widespread attention as a potentially useful agent for preventing cancer and cardiovascular diseases $(1,2)$.

The main quercetin glycosides in onion are quercetin- $4^{\prime}-\mathrm{O}-\beta$-glucoside $\left(\mathrm{Q} 4^{\prime} \mathrm{G}\right)$ and quercetin-3, $4^{\prime}$ $\mathrm{O}-\beta$-diglucosides $\left(\mathrm{Q} 3,4^{\prime} \mathrm{G}\right)(3,4)$. These two flavonoids, $\mathrm{Q} 4^{\prime} \mathrm{G}$ and $\mathrm{Q} 3,4^{\prime} \mathrm{G}$, account for $85 \%$ of the total amount of onion flavonoids. Although the relation between onion intake and the risk of cancer was not clarified in previous studies (5-7), it has been found that the flavonoids in onion have a good effect on human health. Recently, the significance of food functionality in our health has been discussed as a new field of nutrition and flavonoids are recognized as an important food factor for cancer prevention (8).

Generally, flavonoids in vegetables and fruits exist in the form of glycosides. During the process of digestion, most flavonoid glycosides pass into the small intestine, and are decomposed by the intestinal microflora in the colon (9). Some of them are absorbed from the small intestine after hydrolysis (10) and work to prevent the oxidation of LDL and oxidative damage (11-13). Onion, which is a very popular vegetable around the world, is important to the flavonoid intake. The consumption of $300 \mathrm{~g}$ of onion per day was shown to clearly increase the amount of quercetin in plasma (10). In addition, onion is cooked by various methods. In the cooking process, antioxidative vitamins such as ascorbic acid and $\alpha$-tocopherol are decomposed $(14,15)$. It is also suggested that flavonoids are decomposed in cooking.
For understanding of flavonoid absorption and digestion, it is essential to determine the loss of flavonoids in cooking processes. Recent research has used fried onion as an onion supplement for the study of quercetin metabolism $(12,16)$. Some researchers have suggested that boiling affects the content of quercetin glucosides in onion, but the effects were not significant $(17,18)$. By comparing the effects of each cooking method on the content of flavonoids in onion, we identified the most effective cooking method for ingesting quercetin conjugates from onion. In this study, we demonstrate the effect of several cooking methods on the content of flavonoid compounds in cooked onions and the effect of additives on boiling.

\section{MATERIALS AND METHODS}

Materials. Yellow onions grown in Awaji, Hyogo Prefecture, were obtained from a wholesale market in Osaka, Japan. Methanol and ethyl acetate were obtained from Katayama Chemicals (Osaka, Japan) and Wako Pure Chemicals (Osaka, Japan), and used after distillation. Phenol reagent was purchased from Nacalai Tesque (Kyoto, Japan). Distilled water for HPLC analysis was filtered through a membrane filter (cellulose acetate, pore size $0.2 \mu \mathrm{m}$, Advantec, Tokyo, Japan) and degassed before use. Standard quercetin and pectin were from Sigma Chemical Co. (Poole, UK) and gallic acid was from Katayama Chemicals. Other solvents and reagents were obtained from Wako Pure Chemicals.

Cooking methods

Frying: About $2 \mathrm{~kg}$ of onions ( 4 or 5 bulbs) were cleaned without water, peeled, and minced in a food 
processor. An open frying pan (diameter $32 \mathrm{~cm}$ ) was pre-heated to $150^{\circ} \mathrm{C}$ on an electric cooker $(1,200 \mathrm{~W})$, and the minced onion (300 g) was put into it. Cooking times were 5, 20, and $40 \mathrm{~min}$. Corn oil and butter were added to $7 \%$ of the onion. As a control, minced onion was fried without oil on the pan. Corn oil and butter for frying were purchased from a local market in Osaka.

Microwave cooking: Onions were prepared and minced in a food processor the same as for frying. The microwave oven used was a Sharp Model RE-122 (500 W, Osaka, Japan). The frequency of radiation was 2,450 MHz. Minced onion (50 g) was placed in a petri dish (diameter $9.5 \mathrm{~cm}$ ) covered with commercial plastic food wrap (polyvinilidene chloride, $10 \mu \mathrm{m}$ in thickness, Kureha Chemicals, Tokyo, Japan) and microwaved for 30, 60, and 180 seconds.

Boiling: Distilled hot water $(200 \mathrm{~mL})$ and minced onion $(100 \mathrm{~g})$ were put into a beaker $(300 \mathrm{~mL})$, covered with a watch glass, and were individually boiled for 5 , 20 , and $40 \mathrm{~min}$ on an electric heater $(1,200 \mathrm{~W})$. Additional reagents were used to the weight of $1 \%$ of water.

\section{Extraction and analytical methods}

Extraction: We prepared two types of onion extract. One was prepared for the estimation of ascorbic acid content, and the other was for the assay of the total phenol compounds and flavonoids. The extract solution for ascorbic acid measurement was prepared as follows: Cooked onions $(2.0 \mathrm{~g})$ were triturated with 5\% metaphosphoric acid solution. The supernatant was collected after centrifugation $3,000 \mathrm{rpm}$, for $5 \mathrm{~min}-$ utes). The total volume was filled up to $50 \mathrm{~mL}$ with $5 \%$ metaphosphoric acid solution. The sample for ascorbic acid assay was kept at $4^{\circ} \mathrm{C}$ in a refrigerator. After preparing the extract for total phenol compounds and flavonoids analysis, some of the cooked onion (30.0 g) was freeze-dried. In the case of frying with corn oil and butter, cooked and freeze-dried onions were washed with $n$-hexane $(50 \mathrm{~mL})$ three times before extraction. The freeze-dried cooked onion $(1.0 \mathrm{~g})$ was extracted with $70 \%$ methanol $(50 \mathrm{~mL})$ at $30^{\circ} \mathrm{C}$ for $20 \mathrm{~h}$ in the dark. After being filtered through a filter paper (No. 2, Advantec, Tokyo, Japan), the extract was evaporated and filled up to $20 \mathrm{~mL}$ with $70 \%$ methanol. After adding twice the volume of methanol, the filtered boiling water was kept at $-20^{\circ} \mathrm{C}$. The boiling water was filtered through a No. 2 filter paper.

Analysis condition of HPLC and hydrolysis: Total phenol contents were evaluated by a slightly modified Folin-Denis method (19). Gallic acid was used as a standard. Ascorbic acid and flavonoids were measured using HPLC analysis. For measuring compounds, two HPLC apparatuses were used: One was a Gulliver intelligent system with UV detector (UV-970, Jasco, Tokyo, Japan), and the other system consisted of a pump (PU980, Jasco), UV detector (638-41, Hitachi, Tokyo, Japan), and integrator (870-IT, Jasco). Ascorbic acid was analyzed using an Inertsil ODS-3 column $(4.6 \times$ $150 \mathrm{~mm}$, pore size $5 \mu \mathrm{m}$, GL Sciences, Tokyo, Japan). The eluent used was $20 \mathrm{~mm}$ phosphate buffer, $\mathrm{pH} 2.5$, and monitored at $245 \mathrm{~nm}$. The analysis conditions of quercetin glucosides were the same as in a previous paper $(20)$.

The total quercetin content was determined after acid hydrolysis of extracted flavonoids with $2 \mathrm{~N}-\mathrm{HCl}$ for $30 \mathrm{~min}$ in boiling water, and extracted with ethyl acetate. The analysis of quercetin by HPLC followed a previous method (20). HPLC chromatograms of flavonoid compounds were quantified by fast atom bombardment-mass spectrometry (FAB-MS) after peak preparation.

Statistics: Statistical analysis was carried out using Stat View 4.5 (Hulinks, Tokyo, Japan) on a Macintosh. One-way repeated-measures ANOVA was used with Scheffe's multiple analysis of variance. Multivariate analysis was performed using hierarchical cluster analysis with Pirouette 2.3 (InfoMetrix, Woodinville, WA, USA) on Windows 95. The significance level was at 0.05 .

\section{RESULTS}

\section{Analysis of cooking methods}

We examined the effects of three cooking methods on the amount of antioxidative compounds in onion. In case of frying, we used three methods: without oil (control), with corn oil, and with butter. Ascorbic acid, which is a hydrophilic antioxidant, is unstable under heat treatment. Degradation of ascorbic acid during cooking reflected the precision of our cooking (Table 1). The main flavonoids in onion were quercetin glycosides. The total amount of quercetin in fried onion is shown in Fig. 1. The content of total quercetin after acid hydrolysis was not significantly altered after $40 \mathrm{~min}$ of frying. More than $80 \%$ of flavonoid compounds remained in the fried onion after heating. This indicated that the method of frying had little effect on the quercetin content in onion, regardless of the type of oil or butter. In addition, total phenol content was suggested to increase reductant substances in cooking. During all frying of onion in our cooking, there was no significant browning. The temperature measured at the center of the pan during frying was below $150^{\circ} \mathrm{C}$.

On the other hand, the total quercetin content was increased 1.5 times by microwave heating for $1 \mathrm{~min}$. It was supposed that quercetin glycosides were extracted from cooked onion more easily under microwave heating than from fresh onion. The contents of total phenol and ascorbic acid did not change significantly (data not shown).

As shown in Fig. 2, the content of $Q 4^{\prime} G$, one of the main flavonoid glucosides in onion, was decreased by boiling. It was observed that $\mathrm{Q}^{\prime} \mathrm{G}$ in onion was transferred to the water without decomposition, although ascorbic acid was clearly decreased by boiling (data not shown).

Effect of additional reagents on the content of flavonoid glucosides in boiled onion

The effect of additives on the amounts of quercetin in the form of free and quercetin glucosides in onion is shown in Figs. 3-1 and 3-2. Cooking time was set as 
Table 1. Degradation of the content of ascorbic acid in fried onion.

\begin{tabular}{|c|c|c|c|}
\hline \multirow{2}{*}{ Frying method } & \multirow{2}{*}{ Cooking time (min) } & \multicolumn{2}{|c|}{ Ascorbic acid } \\
\hline & & Mean \pm SD (mg) & Relative (\%) \\
\hline \multirow[t]{4}{*}{ Control (without oil) } & 0 & $2.8 \pm 0.7^{\mathrm{a}}$ & 100 \\
\hline & 5 & $2.0 \pm 0.2^{b}$ & 66 \\
\hline & 20 & $1.2 \pm 0.4^{\mathrm{c}}$ & 59 \\
\hline & 40 & $0.7 \pm 0.1^{\mathrm{d}}$ & 22 \\
\hline \multirow[t]{4}{*}{ Corn oil } & 0 & $3.0 \pm 0.1^{\mathrm{a}}$ & 100 \\
\hline & 5 & $2.3 \pm 0.6^{\mathrm{b}}$ & 73 \\
\hline & 20 & $1.7 \pm 0.8^{\mathrm{c}}$ & 42 \\
\hline & 40 & $1.0 \pm 0.1^{\mathrm{d}}$ & 24 \\
\hline \multirow[t]{4}{*}{ Butter } & 0 & $4.3 \pm 1.4^{\mathrm{b}}$ & 100 \\
\hline & 5 & $2.8 \pm 0.8^{\mathrm{b}}$ & 78 \\
\hline & 20 & $2.4 \pm 0.7^{\mathrm{a}}$ & 46 \\
\hline & 40 & $0.9 \pm 0.3^{a}$ & 34 \\
\hline
\end{tabular}

The addition of oils to frying onion is $21 \mathrm{~g}$ ( $7 \%$ of onion). The amount of ascorbic acid includes the content of dehydroascorbic acid and ascorbic acid. Data were expressed as mg per $100 \mathrm{~g}$ fresh onion bulbs. Values are the means \pm standard deviation of 7-10 determinations. Those in the same column with different superscript letter are significantly different at $p<0.05$.

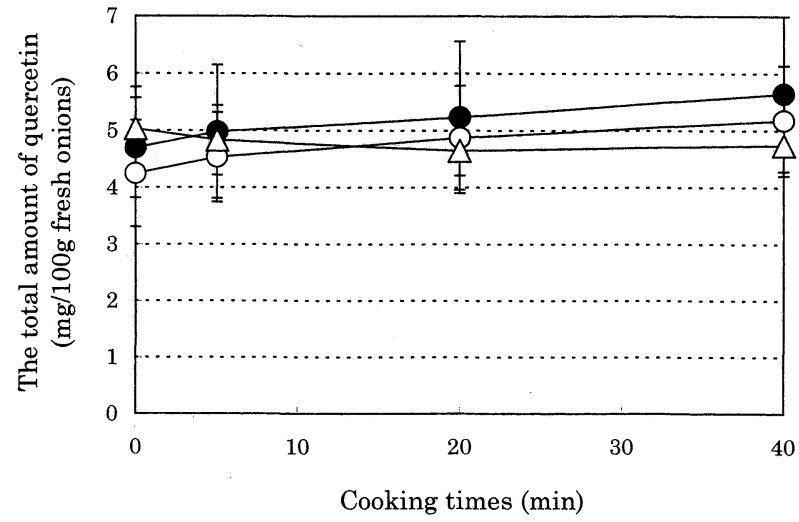

Fig. 1. Changes of total quercetin in onion by different frying method. Onion bulbs $(300 \mathrm{~g})$ were fried without $(\bigcirc)$ and with $7 \%$ of corn oil $(\bullet)$ or butter $(\triangle)$. The amount of total quercetin includes quercetin glycosides and free quercetin. Values are the means \pm standard deviation of 7-10 replicate analyses. Data was expressed as mg per $100 \mathrm{~g}$ fresh onions.

20 min referring to the data of Fig. 2. In this experiment, we had selected substances used in domestic cooking. A higher content of $Q 3,4^{\prime} \mathrm{G}$ remained than that of quercetin with the addition of gelatin, sodium chloride, ferrous sulfate (II), and ferrous sulfate (III) (Fig. 3-1). The supplement of ferrous compounds remarkably decreased the content of flavonoids. Q3,4'G was more stable than other flavonoids under the addition of ferrous compounds. After the addition of ferrous sulfate (III), quercetin could not be detected in our system. Additional gelatin improved the amount of $\mathrm{Q} 3,4^{\prime} \mathrm{G}$ more than that of other flavonoids. On the other hand, quercetin content remained higher than that of the other glucosides with the addition of calcium chloride, glutamic acid, and oxalic acid (Fig. 3-2). The solution of $1 \%$ calcium chloride showed a $\mathrm{pH}$ of 6.6 . The solution of oxalic acid showed a $\mathrm{pH}$ of 1.6. Thus, oxalic acid was

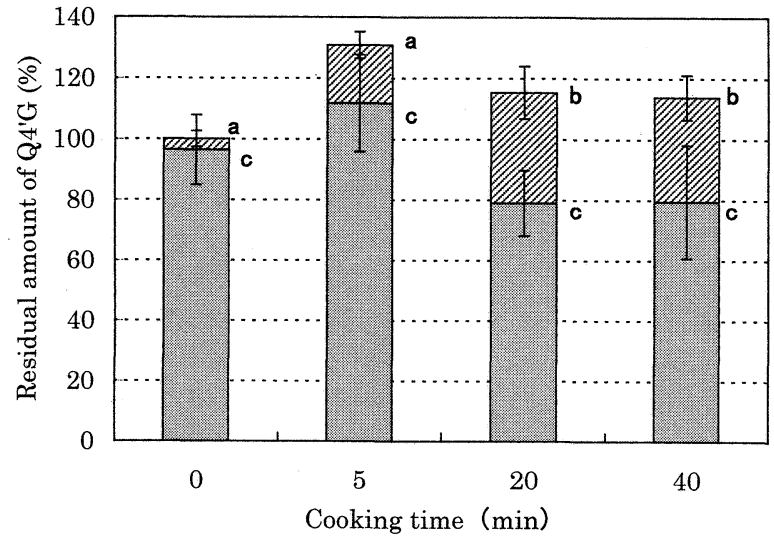

Fig. 2. Changes in quercetin $4^{\prime}-0-\beta$-glucoside during onion boiling. The hatched and shaded columns show the relative amounts of $\mathrm{Q} 4^{\prime} \mathrm{G}$ compounds in cooking water and onion, respectively, at various boiling times. Values on a column with different superscript letters are significantly different at $p<0.05$. Each value is the mean \pm standard deviation of three replicate analyses.

thought to cause acid hydrolysis for quercetin glycosides. The addition of daily seasonings such as sodium chloride and soy sauce caused a lowering of $\mathrm{pH}$, too. With the addition of sodium chloride, the solution showed $\mathrm{pH}$ 5.2, and in the case of glutamic acid, it was $\mathrm{pH}$ 3.3. Quercetin was increased by the addition of glutamic acid as shown in Fig. 3-2.

To clarify the co-relation of each additional compound, we applied the hierarchical cluster analysis to the survival rate of $\mathrm{Q} 4{ }^{\prime} \mathrm{G}$, as shown in Fig. 4. The addition of ferrous ions caused different effects than the other reagents. The dendrograms patterns of the other flavonoids were not so different.

\section{DISCUSSION}

Onions are very common vegetables and are cooked by various methods. Moreover, they are recognized as a 


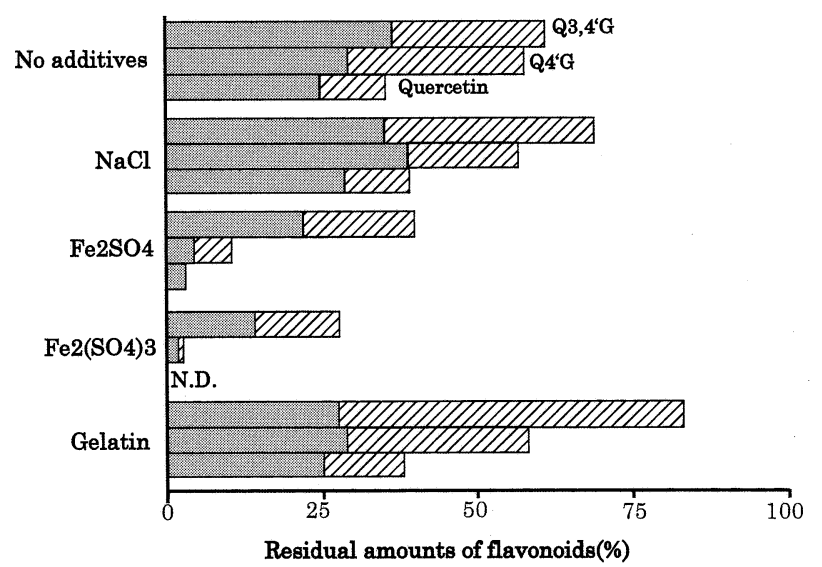

Fig. 3-1.

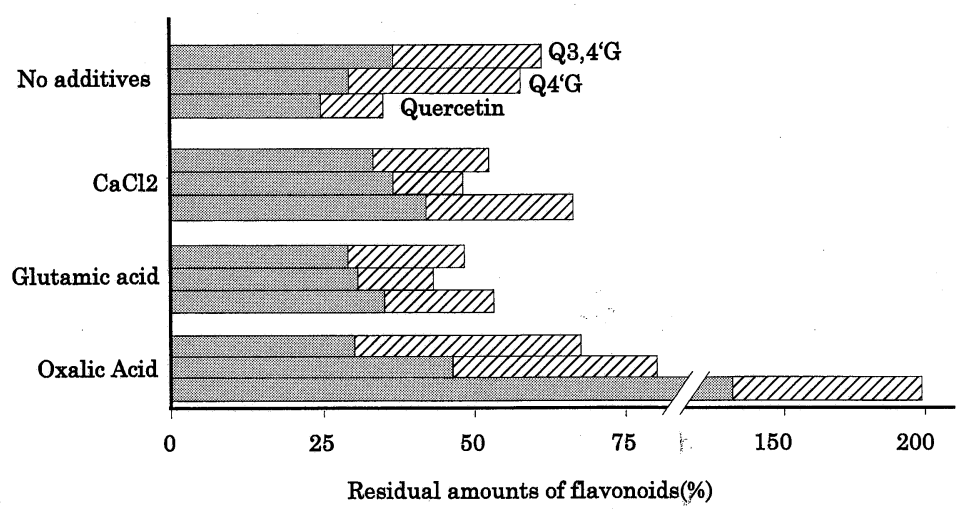

Fig. 3-2.

Fig. 3. Effect of additives on the contents of onion flavonoids in boiling. The amount of additive was $1 \%$ of the boiling water. The top, middle and bottom columns for each additive indicates the contents of Q3,4'G, Q4'G, and free quercetin, respectively. The shaded and hatched areas of each column show the relative amounts of quercetin and its glucosides in onion and cooking water. For the group of additives shown in Fig. 3-1, Q3, $4^{\prime} \mathrm{G}$ is better retained than $\mathrm{Q} 4^{\prime} \mathrm{G}$ and quercetin. In addition, the group of additives for which quercetin is better retained than $\mathrm{Q} 4^{\prime} \mathrm{G}$ and $\mathrm{Q} 3,4^{\prime} \mathrm{G}$ is shown in Fig. 3-2. 'N.D.' means 'not detected'.

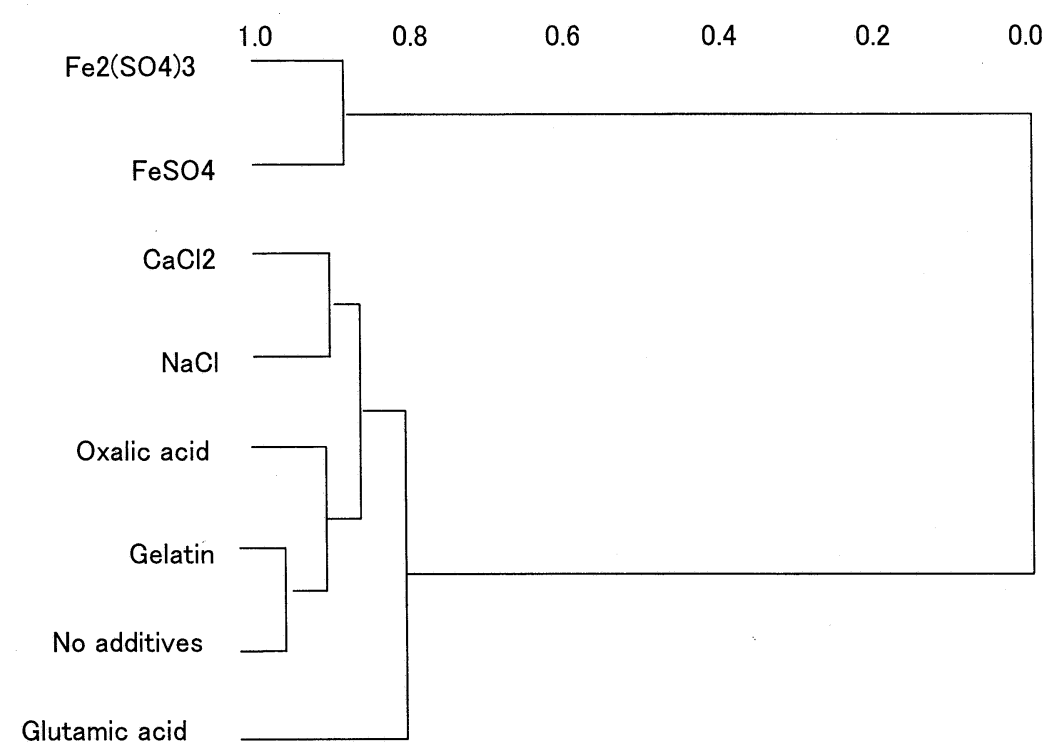

Fig. 4. Dendrogram of hieratical cluster analysis based on the data of $Q 4^{\prime} \mathrm{G}$ in cooked onion and water. 
good source of quercetin. We investigated the effect of different cooking techniques on quercetin conjugates.

A previous study showed that frying with sunflower oil had remarkable effects on the content of quercetin glucosides. Furthermore, an overall loss of flavonol derivatives was observed in the tissue after more than $15 \mathrm{~min}$, frying, which caused extensive browning (17). We tried three types of frying for $40 \mathrm{~min}$ with corn oil and butter, but there was no significant difference. In addition, browning of onion did not occur to any remarkable extent during prolonged frying. The increase of temperature on the surface of the pan took place slowly and there were few triggers for browning in cooking onion. Considered that the use of fluorocarboncoated frying pans is very popular in Japan (21), this data is useful in daily cooking. Thus, we concluded that flavonoid glycosides resist heating with oil and butter.

In the case of microwave cooking, $64 \%$ of quercetin had been lost in previous data (22). However, they added water for cooking before the microwave heating. The addition of much water in microwave cooking is considered the same as cooking by boiling. By covering the top of the dish, onion can be cooked efficiently without the addition of water. Other studies have shown equal or better retention of some vitamins $\left(B_{1}, B_{2}, B_{6}\right.$, $\mathrm{B}_{12}, \mathrm{C}$ and folic acid) after microwave heating than after other domestic heating methods (23-25). Taking into account the nutritional and bioactive substances in cooked foods, microwave cooking is the recommended method.

As shown in Figs. 3-1, and 3-2, we demonstrated that the residual amounts of $Q 3,4^{\prime} \mathrm{G}$ and $\mathrm{Q} 4^{\prime} \mathrm{G}$ in boiled onion were $30-40 \%$ of fresh onion. Considering these amounts to be in the boiled water part, we concluded that more than $70 \%$ of quercetin glucosides remain after boiling. As shown in Fig. 2, we discovered the amount of $4^{\prime} \mathrm{G}$ was not changed significantly by boiling. We can detect $Q 4^{\prime} \mathrm{G}$ in boiling water in the form of glucoside. Therefore, it is suggested that onion soup is a good source of flavonoids. Previous data also showed that domestic cooking of onion bulbs in the U.K. does not result in gross changes in quercetin glycosides (17). Our data also indicated the same results.

Cooking onions at home, it is usual to add some seasonings or other foodstuffs. Thus, we examined the effect of additives on the flavonoid content in boiled onions. Consequently, extra compounds were divided into two groups. The first group was composed of sodium chloride, ferrous compounds, and gelatin (Fig. 3-1). It was elucidated that $\mathrm{C} 3-\mathrm{OH}$ and $\mathrm{C}^{\prime}{ }^{\prime}-\mathrm{OH}$ with the conformation of quercetin were important to scavenge radicals and chelate ferrous ions for antioxidative activity $(26,27)$. Q3,4'G substituted two glucosides with the $\mathrm{C} 3-\mathrm{OH}$ and $\mathrm{C}^{\prime}-\mathrm{OH}$ positions, so the reactivity toward the ferrous ions might not be high. The addition of $1 \mu \mathrm{M}$ of ferrous chloride (II) to boiling water did not facilitate the oxidation of $\mathrm{Q}^{\prime} \mathrm{G}$ and $\mathrm{Q} 3,4^{\prime} \mathrm{G}$ in onion (18). The concentration of $1 \%$ ferrous sulfate (III) corresponded to a mole concentration of $25 \mathrm{~mm}$. At a high concentration of ferrous ions, it is possible to produce flavonoid oxidation. In our HPLC systems, we could not measure the compounds that chelate forms with flavonoids. In general, the chelate form of flavonoids and binding flavonoids exist in tissues. It is interesting to compare the bioactivity with that of the free form of flavonoids. On the other hand, there are many types of ferrous compounds in food. Further study will be needed to clarify the effect of foodstuffs containing ferrous compounds. Substantial work was carried out on gelatin and polyphenol interactions and it indicated that it might be possible to combine more $\mathrm{OH}$ groups in the molecule with gelatin (28). Accordingly, Q3,4'G has the possibility to be combined easily with gelatin compared with other flavonoids.

The second group of compounds summarized in Fig. 3-2 was composed of calcium chloride, glutamic acid, and oxalic acid. The oxalic acid was caused by the acid hydrolysis of quercetin glucosides, causing a strongly acidic condition. Consequently, not only $\mathrm{Q} 4^{\prime} \mathrm{G}$ and Q3,4'G but also other quercetin glycosides in onion were hydrolyzed, and a high amount of quercetin was detected. The relationship of $\mathrm{pH}$ and hydrolysis of flavonoid glucosides in daily cooking is not clear, but the hydrolysis of flavonoid glycosides may depend on the cooking method.

We used hierarchical cluster analysis to investigate the relations and consider the characteristics of additive compounds (Fig. 4). However, we did not find clear differences in this experiment, although the group with the addition of ferrous ions was distinguishable from the others.

The composition of flavonoids in the Japanese diet (29) has been investigated, but it is very difficult to determine the quantity of flavonoids in a dish. In the case of cooking onion for various dishes, it is necessary to study the effect of cooking method on the flavonoid content when cooking onion under several conditions.

\section{Acknowledgement}

We wish to express our special thanks to the Center for Instrument Analysis in Osaka Kyoiku University.

\section{REFFERENCES}

1) Williamson G, Geoff WP, Uda Y, Price KR, Rhodes MJ. 1996. Dietary quercetin glucosides: antioxidant activity and induction of the anticarcinogenic phase II marker enzyme quinone reductase in Hepalclc 7 cells. Carcinogenesis 17: 2385-2387.

2) Hollman PC, Katan MB. 1998. Bioability and health effects of dietary flavonols in man. Arch Toxicol Suppl 20: 237-248.

3) Tsushida T, Suzuki M. 1995. Isolation of flavonoid-glucosides in onion and identification by chemical synthesis of the glycosides (flavonoid in fruits and vegetables part I). Nippon Shokuhin Kagaku Kogaku Kaishi 42: 100-108 (in Japanese with English summary).

4) Tsushida T, Suzuki M. 1996. Content of flavonol glucosides and some properties of enzymes metabolizing the glucosides in onion. Nippon Shokuhin Kagaku Kogaku Kaishi 43: 642-649.

5) Katan J, Mensink RP, Cox FJJ, Harryvan JL, Hovenier R, Hollman PCH, Katan MB. 1998. Effects of the 
flavonoids quercetin and apigenin on hemostasis in healthy volunteers: results from an in vitro and dietary supplement study. Am J Clin Nutr 67: 255-262.

6) Hertog MGL, Kromhout D, Aravanis C, Blackburn H, Buzina R, Fidanza F, Giampaoli S, Jansen A, Menotti A, Nedeljkovic S, Pekkarinen M, Simic BS, Toshima H, Feskens EJM, Hollman PCH, Katan MB. 1995. Flavonoid intake and long-term risk of coronary heart disease and cancer in the seven countries study. Arch Intern Med 155: 381-386.

7) Dorant E, Brandt PA, Goldbohm RA, Sturmans F. 1996. Consumption of onions and a reduced risk of stomach carcinoma. Gastroenterology 110: 12-20.

8) Terao J. 1999. Dietary flavonoids as plasma antioxidants on lipid peroxidation. Significance of metabolic conversion. In: Antioxidant Foods: Supplements In Human Health (Packer L, Hiramatsu M, Yoshikawa T, eds), p 255-268. Academic, New York.

9) Griffiths LA. 1982. Mammalian metabolism of flavonoids. In: The Flavonoids-advances in research (Harbone JB and Mabry TJ, eds), p 681-717, Chapman and Hall, London, UK.

10) Moon JH, Nakata R, Oshima S, Inakuma T, Terao J. 2000. Accumulation of quercetin conjugates in blood plasma after the short-term ingestion of onion by women. Am J Physiol Regulatory Integrative Comp Physiol 279: R461-R467.

11) Silva EL, Tsushida T, Terao J. 1998. Inhibition of mammalian 15-lipoxygenase-dependent lipid peroxidation in low-density lipoprotein by quercetin and quercetin monoglucosides. Arch Biochem Biophys 349: 313-320.

12) McAnlis GT, McEneny J, Pearce J, Young IS. 1999. Absorption and antioxidant effects of quercetin from onions in man. Eur J Clin Nutr 53: 92-96.

13) Lean ME, Noroozi M, Kelly I, Bruns J, Talwar D, Sattar N, Crozier A. 1999. Dietary flavonols protect diabetic human lymphocytes against oxidative damage to DNA. Diabetes 48: 176-181.

14) Rumm-Kreuter D, Demmel I. 1990. Comparison of vitamin losses in vegetables due to various cooking methods. J Nutr Sci Vitaminol 36: S7-S15.

15) Wyatt CJ, Carballido SP, Mendez, RO. 1998. $\alpha$ - and $\gamma$ tocopherol content of selected foods in the Mexican diet: effect of cooking losses. J Agric Food Chem 46: 4657-4661.

16) Aziz AA, Edwards CA, Lean ME, Crozier A. 1998. Absorption and excretion of conjugated flavonols including quercetin- $4^{\prime}-0$ - $\beta$-glucosides and isorhamnetin$4^{\prime}$-O- $\beta$-glucoside by human volunteers after the consumption of onions. Free Radic Res 29: 257-269.
17) Price KR, Bacon JR, Rhodes MJC. 1997. Effect of storage and comestic processing on the content and composition of flavonol glucosides in onion (Allium cepa L.). J Agric Food Chem 45: 938-942.

18) Hirota S, Shimoda T, Takahama U. 1998. Tissue and spatial distribution of flavonol and peroxidase in onion bulbs and stability of flavonol glucosides during boiling of the scales. J Agric Food Chem 46: 3497-3502.

19) Slinkard K, Singleton VL. 1977. Total phenol analysis: automation and comparison with manual methods. Am J Enol Vitic 28: 49-55.

20) Ioku K, Pongpiriyadacha Y, Konishi Y, Takei Y, Nakatani N, Terao J. 1998. $\beta$-Glucosidase activity in the rat small intestine toward quercetin monoglucosides. Biosci Biotechnol Biochem 262: 1428-1431.

21) Ishikawa M. 1996. Studies on the cooking behavior under the home. - Utilization of cooking equipments and machines for family dietary life. Bulletin of Aoba Gakuen Junior College 21: 13-21.

22) Crozier A, Lean MEJ, McDonald MS, Black C. 1997. Quantitative analysis of the flavonoid content of commercial tomatoes, onions, lettuce, and celery. J Agric Food Chem 45: 590-595.

23) Severi S, Bedogni G, Zoboli GP, Manzieri AM, Poli M, Gatti G, Battistini N. 1998. Effects of home-based food preparation practices on the micronutrient content of foods. Eur J Cancer Prec 7: 331-335.

24) Watanabe F, Abe K, Fujita T, Goto M, Hiemori M, Nakano Y. 1998. Effects of microwave heating on the loss of vitamin B12 in foods. J Agric Food Chem 46: 206-210.

25) Kwiatkowska CA, Finglas PM, Faulks RM. 1989. The vitamin content of retail vegetables in the UK. J Human Nutr Dietet 2: 159-172.

26) Ioku K, Tsushida T, Takei Y, Nakatani N, Terao J. 1995. Antioxidative activity of quercetin and quercetin monoglucosides in solution and phospholipid bilayers. Biochem Biophys Acta 1234: 99-104.

27) Morel I, Lescoat G, Cogrel P, Sergent O, Pasdeloup N, Brissot P, Cillard P, Cillard J. 1993. Antioxidant and iron-chelationg activities of the flavonoids catechin, quercetin and diosmetin on iron-loaded rat hepatocyte cultures. Biochem Pharmacol 45: 13-19.

28) Siebert KJ, Troukhanova NV, Lynn PY. 1996. Nature of polyphenol-protein interactions. J Agric Food Chem 44: 80-85.

29) Kimira M, Arai Y, Shimoi K, Watanabe S. 1998. Japanese intake of flavonoids and isoflavonoids from foods. J Epidemiol 8: 168-175. 